ARTICLE

https://doi.org/10.1038/s41467-019-08672-6

\title{
Numerous cultivated and uncultivated viruses encode ribosomal proteins
}

\author{
Carolina M. Mizuno', Charlotte Guyomar ${ }^{2}$, Simon Roux (10 ${ }^{3}$, Régis Lavigne ${ }^{4}$, Francisco Rodriguez-Valera (D) ${ }^{5}$, \\ Matthew B. Sullivan ${ }^{6,7}$, Reynald Gillet ${ }^{2}$, Patrick Forterre ${ }^{1} \&$ Mart Krupovic (i) ${ }^{1}$
}

Viruses modulate ecosystems by directly altering host metabolisms through auxiliary metabolic genes. However, viral genomes are not known to encode the core components of translation machinery, such as ribosomal proteins (RPs). Here, using reference genomes and global-scale viral metagenomic datasets, we identify 14 different RPs across viral genomes arising from cultivated viral isolates and metagenome-assembled viruses. Viruses tend to encode dynamic RPs, easily exchangeable between ribosomes, suggesting these proteins can replace cellular versions in host ribosomes. Functional assays confirm that the two most common virus-encoded RPs, bS21 and bL12, are incorporated into 705 ribosomes when expressed in Escherichia coli. Ecological distribution of virus-encoded RPs suggests some level of ecosystem adaptations as aquatic viruses and viruses of animal-associated bacteria are enriched for different subsets of RPs. Finally, RP genes are under purifying selection and thus likely retained an important function after being horizontally transferred into virus genomes.

\footnotetext{
${ }^{1}$ Unité de Biologie Moléculaire du Gène chez les Extrêmophiles, Département de Microbiologie, Institut Pasteur, Paris 75015, France. ${ }^{2}$ Univ Rennes, CNRS, IGDR (Institut de génétique et développement de Rennes) - UMR 6290, F-35000 Rennes, France. ${ }^{3}$ Department of Energy Joint Genome Institute, Walnut Creek, CA 94598, USA. ${ }^{4}$ Univ Rennes, Inserm, EHESP, Irset (Institut de recherche en santé environnement et travail)-UMR_S 1085, PROTIM, F-35000 Rennes, France. ${ }^{5}$ Departamento de Producción Vegetal y Microbiología, Evolutionary Genomics Group, Universidad Miguel Hernandez, Alicante 03550, Spain. ${ }^{6}$ Department of Microbiology, The Ohio State University, Columbus, OH 43210, USA. ${ }^{7}$ Department of Civil, Environmental and Geodetic Engineering, The Ohio State University, Columbus, OH 43210, USA. These authors contributed equally: Carolina M. Mizuno and Charlotte Guyomar. Correspondence and requests for materials should be addressed to M.K. (email: krupovic@pasteur.fr)
} 
$\mathrm{D}$ uring billions of years of co-evolution with their hosts, viruses have evolved numerous strategies to directly modulate metabolic pathways and subvert key cellular biosynthetic machineries, which ensure their successful propagation. For example, ocean viruses that infect cyanobacteria (cyanophages) commonly encode core photosynthetic reaction center proteins, which serve to maintain the complex photosynthetic machinery during infection ${ }^{1,2}$. These and other ocean viruses can similarly manipulate their host's ability to alter central carbon metabolism ${ }^{3}$, uptake phosphate ${ }^{4}$, and cycle nitrogen ${ }^{5,6}$, and sulfur 7,8 - the fundamental building blocks of life. Complementarily, viruses employ a diverse array of host take-over strategies to (i) fight off host defenses by encoding antirestriction-modification or anti-CRISPR genes ${ }^{9,10}$, (ii) control transcription by encoding sigma factors or polymerases themselves ${ }^{11}$, and (iii) affect how proteins are translated. Indeed, many bacterial and some eukaryotic viruses with large double-stranded DNA genomes commonly encode a range of tRNA genes ${ }^{4,12-14}$. While these genes are presumed to boost the translational efficiency and virulence in diverse hosts ${ }^{15,16}$, their importance during infection remains to be demonstrated experimentally. Giant mimiviruses, whose genomes approach the size of small bacterial genomes, carry many typically cellular genes including those for translation initiation, elongation, and termination, as well as a range of aminoacyl-tRNA synthetases ${ }^{17-19}$, among which methionine- and tyrosine-tRNA synthetases have been functionally characterized ${ }^{20}$. A single tRNA synthetase gene is also encoded in the genome of the largest known bacterial virus, Bacillus megaterium myovirus $\mathrm{G}^{21}$, but its function lacks experimental confirmation. Some marine phages encode peptide deformylases, which are involved in post-translational modification $^{22}$ that, at least in cyanophages, may help preferentially produce the phage-encoded D1 photosystem protein ${ }^{23}$. Finally, T7-like podoviruses encode serine/threonine kinases that have been shown to phosphorylate around 90 proteins, including several involved in protein translation, such as host-encoded ribosomal proteins bS1 and bS6, translation initiation factors IF1, IF2, and IF3, and elongation factors $\mathrm{G}$ and $\mathrm{P}^{24,25}$. It was suggested that phosphorylation of these proteins may stimulate translation of the phage late mRNAs. Although it is now clear that viruses have evolved different strategies to tinker with protein translation, the genes encoding proteins that directly participate in the formation of the ribosomes are not yet observed in the genomes of cultured viral isolates. In fact, this feature-ribosome-encoding or not-has been proposed to signify a major divide between cellular life forms and viruses ${ }^{26,27}$. However, viral genome fragments assembled from environmental viral community sequence datasets (viral metagenomes), which vastly expand upon cultured sequence space, suggested that viruses might encode ribosomal proteins, specifically, bS1 and bS21. Though challenges insuring removal of contamination from cellular genomes and the lack of host context available warrants caution about such observations of "cellular features" in metagenome-only datasets ${ }^{22,28}$, the findings are intriguing.

Here we leverage the greater genomic context now available from large-scale metagenomes and genomes to revisit the question of whether viral genomes encode ribosomal proteins (RPs). We identify 14 different RPs across viral genomes arising from cultivated viral isolates and metagenome-assembled viruses. We show that viruses tend to encode RPs known to be easily exchangeable between ribosomes, suggesting these proteins can replace cellular versions in host ribosomes, and confirm this experimentally for the two most common virus-encoded RPs, bS21 and bL12. Ecological distribution of virus-encoded RPs suggests certain level of ecosystem adaptations as aquatic viruses and viruses of animal-associated bacteria are enriched for different subsets of RPs. Overall, these results further blur the borders between viruses and cellular life forms.

\section{Results}

Ribosomal proteins encoded in cultivated virus genomes. To systematically investigate the presence of RP-encoding genes in viral genomes, we first searched available reference genomes of cultivated viruses. Of 106 RP domains (Supplementary Table 1) that seeded our searches, 5 were identified across 16 viral genomes (Table 1). The genes were generally embedded within variable genomic contexts, even for homologous RP genes (Supplementary Fig. 1). Note that throughout this article we use the unified RP nomenclature ${ }^{29}$, where capital letters "S" and "L", respectively, indicate whether the protein is present in the small or large ribosome subunit, whereas the lowercase letters denote that the protein is specific to bacteria (b), eukaryotes/archaea (e), or are universal $(\mathrm{u})$.

We first identified a ribosomal protein eS30 domain, a component of the small $40 \mathrm{~S}$ ribosomal subunit ${ }^{30}$, in the Finkel-Biskis-Reilly murine sarcoma virus (FBR-MuSV), a member of the family Retroviridae. This domain was part of the fau gene fused to an N-terminal ubiquitin-like domain (Supplementary Fig. 2a). FBR-MuSV has acquired the cDNA copy of fau in inverse orientation, and production of the antisense RNA suppresses expression of endogenous fau mRNA, which leads to apoptosis inhibition and induces tumorigenesis ${ }^{30,31}$. Although the viral protein is not translated ${ }^{30}$, the antisense transcript affects the production of the cellular $f a u^{31}$ and thus might have an indirect effect on the ribosome biogenesis.

The remainder of the virus-encoded ribosomal proteins-bS21, bL9, bL12, and ribosome hibernation promotion factor (HPF)were found in bacterial viruses (bacteriophages) infecting proteobacteria (from three different classes) and mycobacteria (phylum Actinobacteria) hosts (Table 1). Though RP-encoding bacteriophage genomes ranged in size between 44.5 and $358.6 \mathrm{~kb}$, only large $(>130 \mathrm{~kb})$ genomes encoded bS21 and HPF, whereas only smaller $(<80 \mathrm{~kb})$ genomes encoded bL9 and bL12 (Table 1$)$. However, many more phage genomes encoding RP would be needed to verify the significance of this observation.

The bS21 homolog was identified in pelagiphage HTVC008M, a myovirus. bS21 is a conserved component of the bacterial $30 \mathrm{~S}$ ribosomal subunit (Fig. 1a) required for the initiation of polypeptide synthesis and mediates the base-pairing reaction between mRNA and $16 \mathrm{~S} \mathrm{rRNA}^{32}$. The viral protein was most similar (54\% identity over the protein length) to the corresponding protein of its host, Pelagibacter ubique (Fig. 1b), an abundant member of the SAR11 clade (class Alphaproteobacteria), which is considered to represent one of the most numerous bacterial groups worldwide ${ }^{33}$. Maximum likelihood phylogenetic analysis showed that bS21 homologs from different families of alphaproteobacteria cluster together and form a sister group to the mitochondrial homolog, consistent with the scenario under which mitochondria have evolved from an alphaproteobacterial ancestor. In this tree, all alphaproteobacterial sequences are basal to the viral protein, strongly suggesting that the phage gene was horizontally acquired from the Pelagibacter host (Fig. 1c).

Ribosomal protein bL9 was identified in Mycobacterium phage $32 \mathrm{HC}$, a siphovirus. bL9 binds to the 23S rRNA and is a component of the large 50S ribosome subunit (Supplementary Fig. 3a). The protein is involved in translation fidelity and is required to suppress frameshifting, and stop codon "hopping" 34 bL9 has a highly conserved architecture consisting of two widely spaced globular RNA-binding domains connected by an elongated $\alpha$-helix ${ }^{35}$. While the C-terminal domain in the viral bL9 homolog has been apparently non-homologously replaced with a 
a

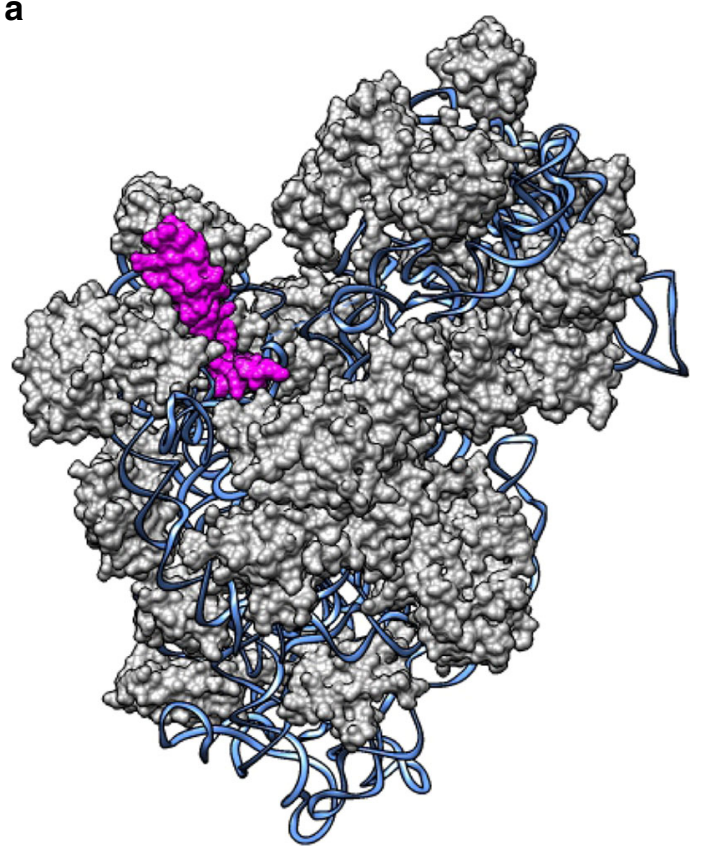

O Alphaproteobacteria O Betaproteobacteria
O Cyanobacteria O Firmicutes
C

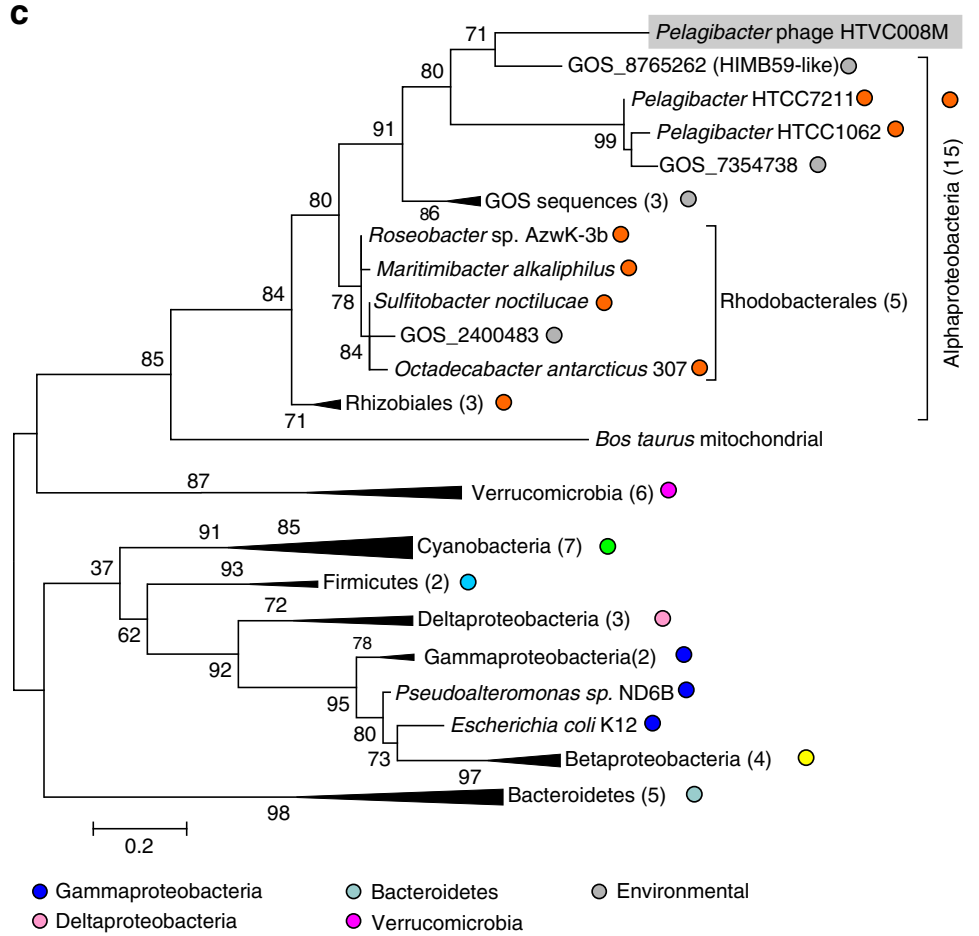

b

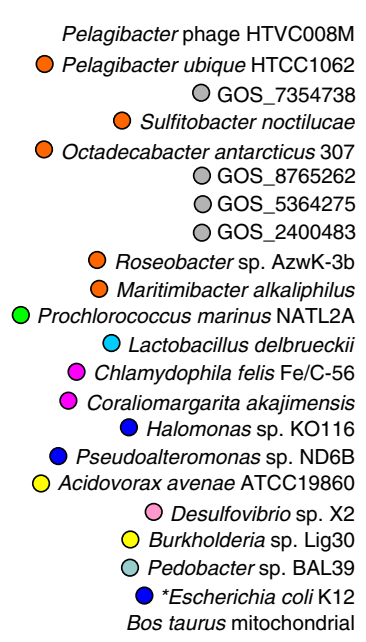

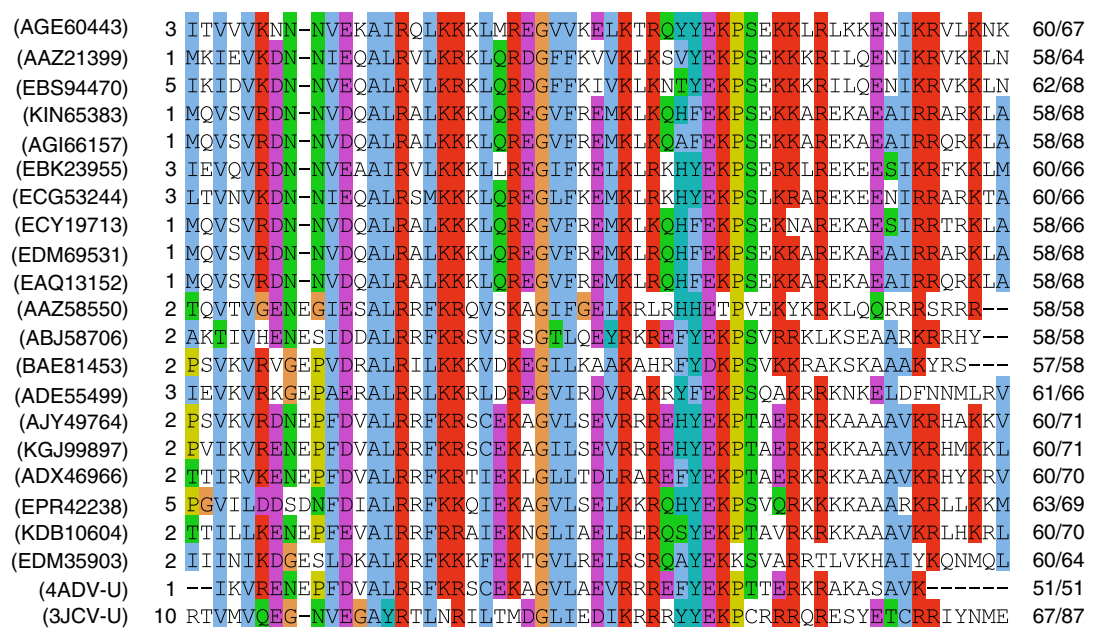

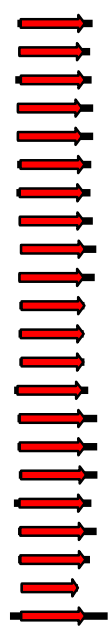

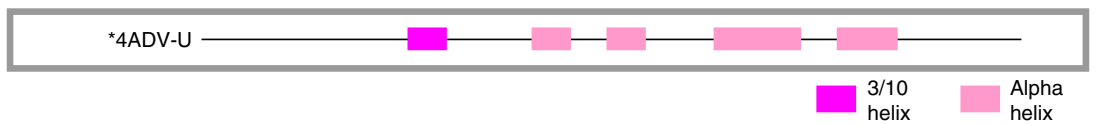

Fig. 1 Virus-encoded ribosomal protein bS21. a Structure of the Escherichia coli 30S ribosomal subunit (PDB id: 4ADV). 16S ribosomal RNA is shown as blue ribbon. bS21 ribosomal protein is highlighted in pink. b Alignment of the ribosomal protein bS21 encoded by pelagiphage HTVC008M with homologs from representatives of distinct bacterial taxa and environmental sequences obtained from the Global Ocean Sampling (GOS) dataset. c Phylogenetic tree of ribosomal protein bS21. Taxonomic affiliations are represented by colored circles (see panel (b) legend)

sequence that lacks known function, the N-terminal RNAbinding domain and part of the $\alpha$-helical spacer are preserved (Supplementary Fig. 2b), suggesting that the viral protein may bind to the $23 \mathrm{~S}$ rRNA.

The next ribosomal protein encoded in sequenced viral genomes was bL12, which was found in 7 phages infecting proteobacteria from three different classes (Table 1). The bL12 proteins participate in the formation of the so-called bL12 stalk, a clearly defined morphological feature in the E. coli 50 S ribosomal subunit, which besides bL12, contains ribosomal proteins uL10 and $\mathrm{uL} 11$ as well as the uL10- and uL11-binding region of the $23 \mathrm{~S}$ rRNA $^{36}$ (Supplementary Fig. 3a). The phage-encoded bL12 domains are similar ( $30-40 \%$ identity) to bona fide cellular ribosomal homologs and contain conserved residues involved in interaction with $\mathrm{uL} 11$ and elongation factors EF-G and EF-Tu (Supplementary Fig. 4a). Although in some phages (e.g., Ralstonia phage RSB3), the bL12 domain spans the entire protein, it was more common to observe these domains variably positioned within much larger polypeptides (up to 724 aa-long; Supplementary Fig. 4b). Notably, searches seeded with sequences flanking the bL12 domain in phage proteins resulted in identification of multiple phage homologs which specifically lack the bL12 domain (Supplementary Fig. 5). For example, proteins encoded by Salmonella phages FSL_SP-058 and FSL_SP-076 contain the 


\begin{tabular}{|c|c|c|c|c|c|c|c|}
\hline Domain & Protein & Name (family) & $\begin{array}{l}\text { Genome } \\
\text { length, kb }\end{array}$ & $\begin{array}{l}\text { RP accession, } \\
\text { length (aa) }\end{array}$ & $\begin{array}{l}\text { Coverage, } \\
\text { identity (\%) } \\
\end{array}$ & $\begin{array}{l}\text { HHpred } \\
\text { Probability (\%) }\end{array}$ & E-value \\
\hline Ribosomal_S21 & bS21 & $\begin{array}{l}\text { Pelagibacter phage HTVCO08M } \\
\text { (M) }\end{array}$ & 147,284 & AGE60443, 67 & 59,46 & 99.81 & 2.7E-19 \\
\hline \multirow{4}{*}{ Ribosomal_L12 } & & Erwinia phage Ea9-2 (P) & 75,568 & AHI60108, 724 & 9,32 & 96.87 & $6.3 \mathrm{E}-03$ \\
\hline & & Ralstonia phage RSB3 $(P)$ & 44,578 & BAN92321, 98 & 59,32 & 99.77 & $2.2 \mathrm{E}-18$ \\
\hline & & Roseophage DSS3P2 $(P)$ & 74,611 & ACL81275, 107 & 62,28 & 99.44 & $3.7 \mathrm{E}-13$ \\
\hline & & $\begin{array}{l}\text { Salmonella phage FSL SP-058 } \\
(P)\end{array}$ & 72,394 & AGF88397, 418 & 16,34 & 96.05 & $1.8 \mathrm{E}-01$ \\
\hline \multirow{5}{*}{ Ribosomal_S30AE } & & $\begin{array}{l}\text { Enterobacteria phage vB EcoM- } \\
\text { FV3 (M) }\end{array}$ & 136,947 & AEZ65272, 105 & 74,35 & 99.92 & $1.5 \mathrm{E}-23$ \\
\hline & & $\begin{array}{l}\text { Escherichia coli bacteriophage } \\
\text { rv5 (M) }\end{array}$ & 137,947 & ABI79209, 105 & 74,33 & 99.96 & $1.3 \mathrm{E}-27$ \\
\hline & & $\begin{array}{l}\text { Escherichia phage } 2 \text { JES-2013 } \\
(M)\end{array}$ & 136,910 & AGM12525, 105 & 74,32 & 99.96 & $3.0 \mathrm{E}-28$ \\
\hline & & $\begin{array}{l}\text { Escherichia coli } 0157 \text { typing } \\
\text { phage } 14(M)\end{array}$ & 131,952 & AKE47110, 105 & 74,33 & 99.96 & $3.4 \mathrm{E}-28$ \\
\hline & & $\begin{array}{l}\text { Escherichia phage vB EcoM FFH2 } \\
(M)\end{array}$ & 139,020 & AEZ65272, 105 & 74,35 & 99.93 & 7.9E-24 \\
\hline
\end{tabular}

bL12 domains, whereas homologous protein from Escherichia phage Pollock lacks this domain, despite conservation of the upstream and downstream regions (Supplementary Fig. 5). Furthermore, in different phage genomes, bL12 proteins were encoded within widely different genomic contexts (Supplementary Fig. 1). These observations suggest that bL12 domain has been acquired by different phages on multiple, independent occasions, with some of these genes possibly being fixed in the phage genomes.

The last ribosomes-associated protein encoded in sequenced viral genomes was the ribosome hibernation promotion factor (HPF), or Ribosomal_S30AE (PF02482) domain-containing protein, which was encoded by 7 phages infecting Cronobacter and E. coli (six closely related phages with $92-97 \%$ average nucleotide identity) (Supplementary Fig. 6). HPF proteins are expressed during stasis and under unfavorable growth conditions; HPF binds ribosomes to stabilize $100 \mathrm{~S}$ dimers that inhibit translation to enable cells to control translational activity without costly alteration of the ribosomal pool ${ }^{37}$. Multiple sequence alignment shows high conservation of the viral and cellular HPF homologs (Supplementary Fig. 7), suggesting that the gene transfer has occurred in a relatively recent past. In the HPF phylogeny, homologs from E. coli phages cluster amidst gammaproteobacterial sequences. By contrast, the more divergent protein encoded by Cronobacter phage clusters with sequences from members of the phylum Firmicutes, though this association is confounded by a potential long-branch-attraction artifact (Supplementary Fig. 8).

Ribosomal proteins detected in viral metagenomes. To place these findings of cultivated virus-encoded RPs into broader ecological context, we searched 424,225 viral contigs from two global metagenomic datasets 8,38 for putative RPs using the same 106 sequence profiles (see Methods). Overall, 13 putative ribosomal protein genes were identified across 1403 contigs (Fig. 2, Supplementary Table 2, Supplementary Fig. 3). By matching CRISPR spacers, comparing k-mer nucleotide frequencies and performing BLASTn homology searches against reference cellular sequences, hosts could be predicted for 74 (5.3\%) of the uncultivated viruses encoding 7 different RPs (Supplementary Data 1). Despite this relatively low fraction of predicted hosts, RPencoding phages are already associated with 8 bacterial phyla (Proteobacteria, Firmicutes, Verrucomicrobia, Bacteroidetes, Deinococcus-Thermus, Thermotogae, Cyanobacteria, and Actinobacteria).

The bS21, bL12, and HPF, which were found in cultivated phages, were also detected in uncultivated phages, with bS21 homologs dominating (88\%) the pool of RPs detected (Fig. 2, Supplementary Table 2). While found in only one cultivated phage (see above), maximum likelihood phylogeny and genome context comparison using these metagenomic data suggested that multiple virus-host exchanges of bS21 protein-coding genes have occurred, likely across various bacterial phyla (Fig. 3). Notably, bS21-encoding viruses were almost exclusively from aquatic samples (90\% of bS21s detected). Such repeated transfers and enrichment in aquatic samples suggest that virus-encoded bS21 proteins likely can provide a direct fitness benefit to aquatic bacteriophages. By contrast, bL12 and HPF were found across a broad range of samples (Fig. 2 and Supplementary Figs 8 and 9), suggesting that their repeated acquisition could be beneficial in multiple types of conditions and hosts.

Another 10 RPs detected in uncultivated viruses were not previously identified in isolate genomes (Supplementary Table 2). Commonly ( $>10$ viral contigs) detected among these are bL31 and bL33. Although the biological function of bL33 remains 


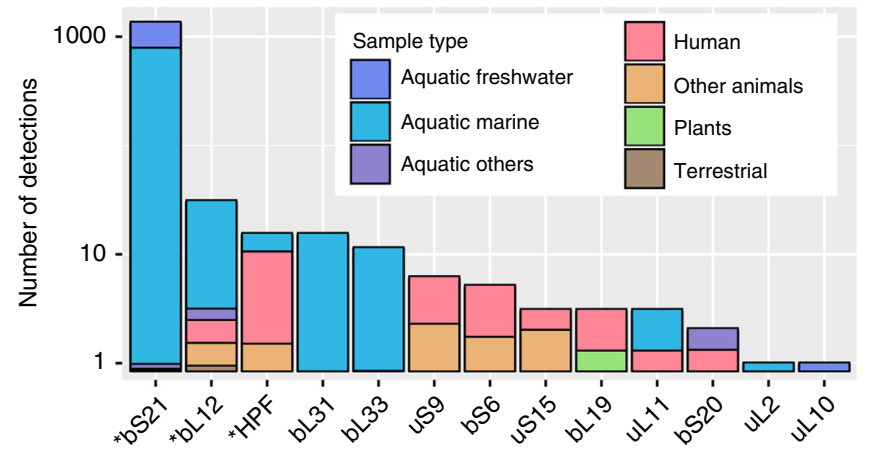

Fig. 2 Detection of ribosomal proteins in uncultivated viral genomes. For each ribosomal protein detected, the total number of detection is shown on the $y$-axis ( $\log _{10}$ scale), and the bar is colored according to the type of samples in which this protein was detected (the sizes of the colored parts are proportional to the number of detections made in each type of samples). Ribosomal proteins also identified in cultivated viruses are identified with stars

obscure $^{39}$, it appears to contact tRNAs in the ribosomal E(exit)site $^{40}$ (Supplementary Fig. 3b), whereas bL31, similar to HPF, plays a role in $100 \mathrm{~S}$ formation, $70 \mathrm{~S}$ association, and translation ${ }^{41}$. As in the case of bS21, viral contigs encoding bL31 or bL33 were almost exclusively detected in aquatic environments (Fig. 2). Maximum likelihood phylogenies and genome context comparisons highlighted a consistent pattern of at least two independent events of virus-host transfers involving viruses infecting different bacterial phyla (Supplementary Figs 10 and 11).

Thus, at this point, there is an emerging picture that ribosomal protein genes acquired through random sampling of host DNA might, in some cases, become fixed in viral genomes. Most $(>99 \%)$ of the viruses contained only a single ribosomal protein gene (exception: 8 uncultivated viral contigs that contained 2; Supplementary Fig. 12), which is clearly not enough for viruses to build functional ribosomes on their own. Presumably, these viruses are merely tweaking ribosomal functioning in their hosts - just as observed for auxiliary metabolic genes (AMGs) whereby viruses typically do not encode complete pathways, but instead only select genes critical for the takeover and/or reprogramming of the host cell $6,7,42$.

RP-encoding genes are carried by temperate and lytic viruses. Given that tRNA genes are more frequently encoded by lytic, as opposed to temperate, viruses ${ }^{15}$, we sought to evaluate whether the acquisition and maintenance of RP-encoding genes is also linked to either the lytic or temperate life-style. Among the 16 RP-encoding cultivated viruses only FBR-MuSV and $\mathrm{Myco}$ bacterium phage $32 \mathrm{HC}$ are temperate (see Methods). Specifically, FBR-MuSV, like all retroviruses, integrates into the cellular genome as an essential step during replication, whereas phage $32 \mathrm{HC}$ encodes a tyrosine recombinase (YP_009009518) predicted to integrate the viral genome into a host tRNA gene ${ }^{43}$. For the majority of RP genes encoded by uncultivated viruses there is not enough genomic data to ascertain their preferential association with either temperate or lytic viruses $(73 \%$ are partial genomes $<20 \mathrm{~kb}$ ). Of 1396 uncultivated virus genome fragments, only 14 were detectably temperate, although these putative temperate viruses encoded 9 of the 13 virus-encoded RPs (Supplementary Table 3). Notably, the bS21 genes appear to be largely encoded by lytic viruses: of the 1310 genomes and large genomic contigs of cultivated and uncultivated viruses encoding bS21, only three (0.23\%) genome fragments carry signature genes of temperate viruses (Supplementary Table 3 ). These results suggest that RP- encoding genes can be acquired by both temperate and lytic viruses, with some of the genes possibly displaying preferential association with lytic viruses. However, additional genomic data will be required to quantitatively assess the dynamics of the RP gene flow between hosts, temperate viruses, and lytic viruses.

Virus-encoded RP genes are under strong purifying selection. Presence of ribosomal protein genes in viral genomes raises a question of what their functions in the course of the infection cycle might be and how do viruses benefit from carrying such genes. The eS30-encoding gene increases the transformation capacity of FBR-MuSV in vitro by twofold, providing clear fitness advantage to the virus ${ }^{30}$. It is conceivable that homologs of other ribosomal proteins might be also beneficial for the bacteriophages that encode them. For instance, it is known that bS21 is necessary during translation initiation step and in the absence of bS21, ribosomes are incapable of binding natural mRNAs ${ }^{32}$. Thus, phage-encoded bS21 might compete with and replace the cellular bS21, ensuring translation of viral transcripts. Similarly, viral bL12 domain proteins might provide interfaces for virus-specific translation factors. Protein bL9 is required for translational fidelity and is involved in suppression of frameshifting. In many members of Caudovirales, production of certain tail components is dependent on programmed translational frameshifting ${ }^{44}$ and a viral copy of bL9 might help to achieve optimal frameshifting in these genes. Finally, it has been demonstrated that stalling of phage protein synthesis is one of the major defense strategies in Bacteroidetes ${ }^{45}$. Thus, viral homologs of HPF and bL31 might compete with the cellular homologs and prevent formation of ribosome dimers, thereby releasing translation inhibition and ensuring that phage transcripts are efficiently translated.

Given what seemed to be reasonable explanations for why viruses might benefit from encoding such genes, we next investigated whether virus-encoded RP genes appeared to be functional. To this end, we calculated the ratio of nonsynonymous polymorphisms per non-synonymous site $(\mathrm{pN})$ to the number of synonymous polymorphisms per synonymous site (pS). Here we used this metric to test if virus-encoded RPs were under purifying or positive selection, where the former $(\mathrm{pN} / \mathrm{pS}$ $<1)$ would indicate selection for a functional protein and the latter $(\mathrm{pN} / \mathrm{pS}>1)$ would indicate that the gene might be in the process of being phased out from the viral genome ${ }^{46}$. We found that wellsampled viral-encoded RP genes $(>10 \times$ coverage, and $\geq 1$ single nucleotide polymorphism, or SNP) had an average $\mathrm{pN} / \mathrm{pS}=0.10$, with $84 \%$ having a $\mathrm{pN} / \mathrm{pS} \leq 0.20$ (Supplementary Table 2 ). This suggests that these genes are under strong purifying selection and thus likely retained an important function after being transferred into virus genomes.

Virus-encoded RPs are incorporated into ribosomes. Although encouraging, the results of these in silico functional assays did not exclude the possibility that the viral RPs function in a different framework compared to their bona fide cellular homologs. Thus, we next explored whether the viral proteins are incorporated into ribosomes, by focusing on 3 RPs encoded by cultivated phages and most frequently detected in uncultivated phage genomes (Fig. 2). These were pelagiphage-encoded bS21, bL12 from Salmonella phage FSL SP-076, and HPF from Escherichia coli phage rv5. Following moderate and controlled expression of the respective viral proteins, $70 \mathrm{~S}$ ribosomes were isolated under high-stringency salt conditions (see Methods) to avoid unspecific association of viral proteins ${ }^{47}$. Judging from the obtained ribosome profiles (Fig. 4a) and transmission electron microscopy (Supplementary Fig. 13), expression of the viral proteins did not affect the $70 \mathrm{~S}$ stability. All examined 


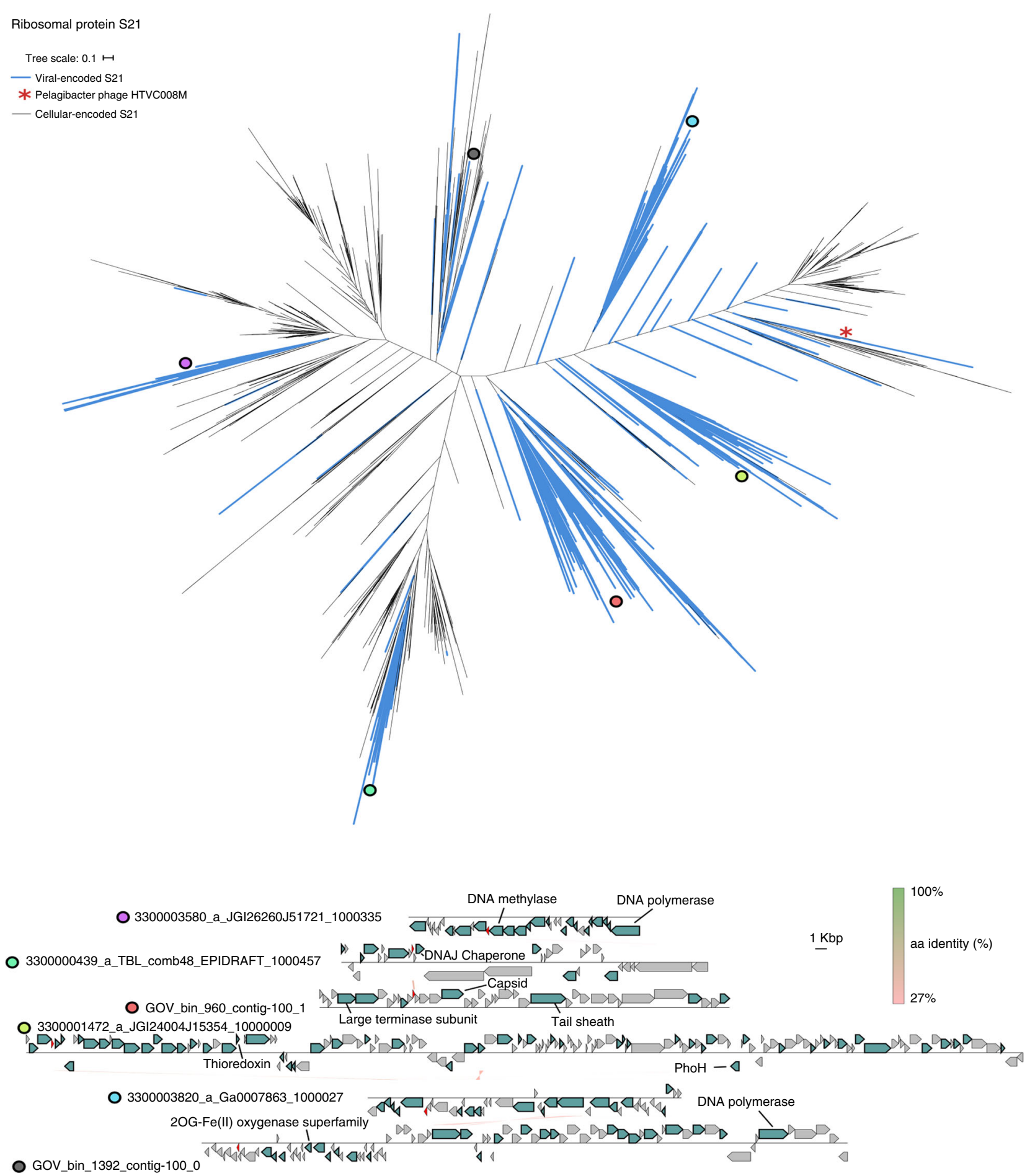

Fig. 3 Ribosomal proteins bS21 identified in uncultivated viral genomes. Top: Phylogenetic tree of ribosomal protein bS21. Viral sequences are highlighted with blue branches. Bottom: Genome comparison of viral contigs encoding ribosomal protein bS21. Comparisons were done at the amino acid level, with the \% identity displayed with a color scale. The predicted bS21-encoding genes are indicated in red. The position of these sequences in the tree (top panel) is indicated with colored circles

samples nearly exclusively contained 70S monoribosomes and a small portion of $100 \mathrm{~S}$ particles (Fig. 4a). Subsequent mass spectrometry (MS) analysis of the $70 \mathrm{~S}$ and $100 \mathrm{~S}$ ribosomes purified on sucrose gradients unequivocally showed that bS21 and bL12 (Table 2, Supplementary Data 2 and 3), but not HPF (Supplementary Data 4), were stably incorporated into the ribosomes when expressed in E. coli. Consistently, there was no discernible effect on the formation of $100 \mathrm{~S}$ particles in cells expressing the viral HPF homolog (Fig. 4a). Notably, HPF was detected using MS in the crude cell extracts (Table 2, Supplementary Data 5), indicating that lack of its incorporation into ribosomes is not due to poor protein expression, but may rather result from other factors, such as inadequate growth phase, genuine loss of ability to bind to ribosomes or dissociation due to stringent washes with salt during ribosome isolation. 

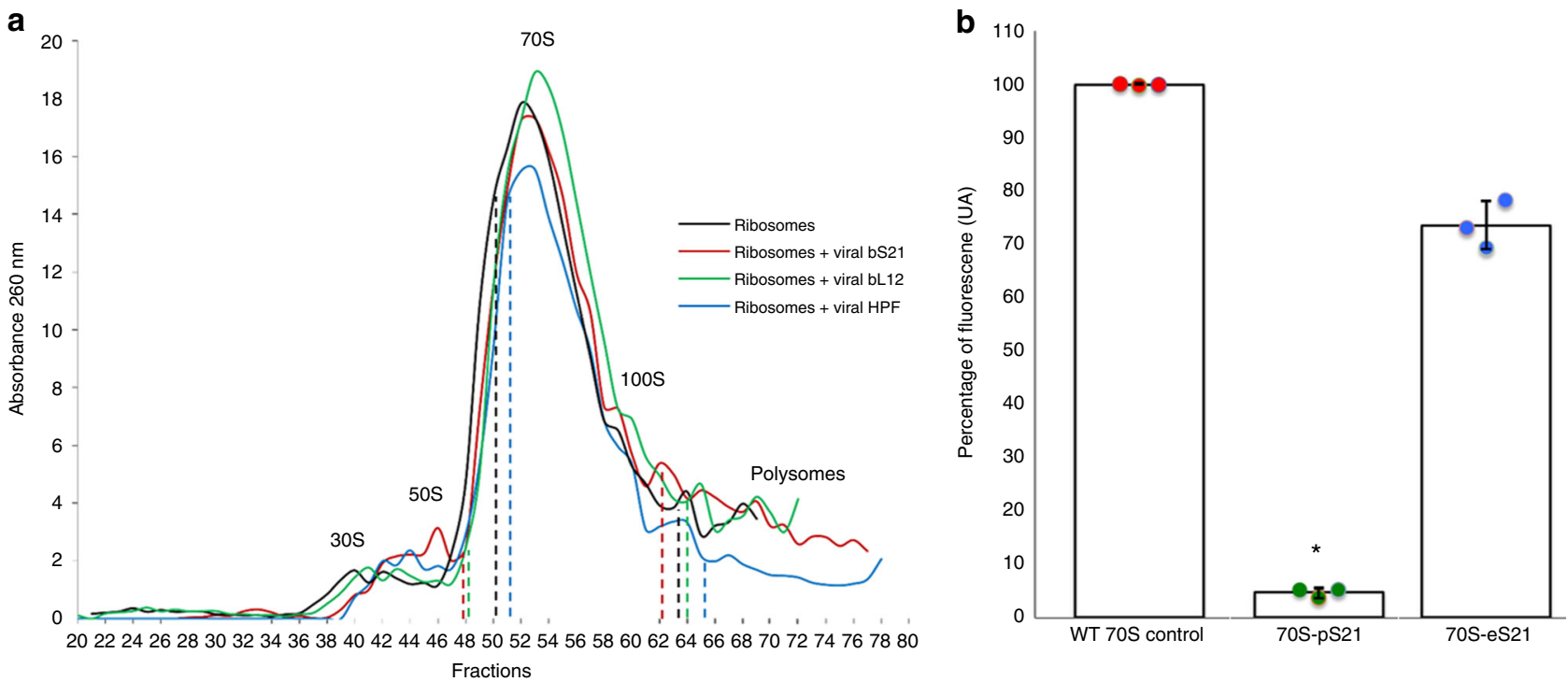

Fig. 4 Ribosome analysis of extracts from NM522 Escherichia coli cells. a Sedimentation profiles of NM522 E. coli ribosomes. Wild-type NM522 E. coli cells (black curve) and cells expressing viral bS21 (red), bL12 (green) or HPF (blue) were lysed and their ribosomes were purified using a 10-50\% sucrose gradient (see experimental section). The dotted lines indicate the fractions that were pooled and further analyzed by mass spectrometry. $\mathbf{b}$ Quantification of in vitro translation of GFP by E. coli 70S ribosomes carrying either E. coli wt bS21 (control), E. coli streptavidin-tagged bS21 (70S-eS21) or viral streptavidin-tagged bS21 (70S-pS21). Translation assay was performed using PURExpress ${ }^{\circledR} \Delta$ Ribosome Kit, complemented with 10 pmol of purified ribosomes and $250 \mathrm{ng}$ of a PCR product encoding for GFP under control of T7 promoter. Fluorescence signal was detected by spectrofluorimetry at 510 nm with an excitation at $485 \mathrm{~nm}$. The percentage of fluorescence was measured with respect to the translation control. The error bar represents the standard deviation measured over three independent experiments. The variance was analyzed using Kruskal-Wallis test followed by a Dunn's multiple comparison test ( $p$-value for 70S-pS21 $=0.0219$ )

Table 2 bS21, bL12, and HPF peptides identified by mass spectrometry in ribosome preparations and crude cell extract

\begin{tabular}{llll} 
Protein, source & Accession number & Peptides in ribosomal fractions & Peptides in cell extract \\
\hline $\begin{array}{l}\text { bS21, Pelagibacter phage } \\
\text { HTVC008M }\end{array}$ & AGE60443 & SITVVVKNNNVE, KKLRLKKE & N.D. \\
$\begin{array}{l}\text { HPF, Escherichia coli phage } \\
\text { rV5 }\end{array}$ & ABI79209 & None & GSDAYEATDR, VENDHQEVMAFIFDNSGK, \\
bL12, Salmonella phage FSL & AGF88397 & VNDDTETYYIDLPYVAR & VENDHQEVM AFIFDNSGK, VKIDFGE \\
SP-O.D.
\end{tabular}

SP-076

*oxidized form of methionine

N.D. not determined

In order to check whether the incorporation of virus-encoded ribosomal proteins alters bacterial translation, we next proceeded to purification of ribosomes carrying bS21 and bL12 viral proteins. Towards this aim, we overproduced the two streptavidin-tagged viral ribosomal proteins in E. coli and the ribosomes containing the tagged viral proteins were purified by affinity. Only ribosomes containing bS21 could be purified, suggesting that the tagged bL12 cannot be efficiently incorporated or that its interaction with the ribosome is not sufficiently strong to allow the purification. The presence of the viral bS21 within the ribosomes was confirmed by MS analysis. The activity of the purified ribosomes was then verified by an in vitro translation assay. The protein synthesis is severely impaired in the presence of viral bS21 ( $\sim \%$ compared to wild-type ribosomes; Fig. $4 \mathrm{~b})$. This impairment is not due to the presence of the affinity tag, because ribosomes containing the streptavidin-tagged E. coli bS21 were still active ( $75 \%$ compared to wild-type ribosomes; Fig. $4 \mathrm{~b})$. The inactivity of ribosomes carrying the viral bS21 suggests that additional virus- or host-encoded factors may be needed for proper translation or that the RP from a phage infecting
Pelagibacter ubique may not be fully compatible with E. coli ribosomes.

Regardless, these results indicate that following their transfer into viral genomes, bS21 and bL12 retained the ability to incorporate into ribosomes, successfully competing with the native cellular counterparts. Whether incorporation of these and other viral RPs modulates protein translation during phage infection remains to be demonstrated by further functional assays both with heterologously expressed RPs as well as in the framework of the infection with the corresponding phages.

\section{Discussion}

The evolution of life is a history of virus-host interactions, an incessant "arms race" between viruses and cells ${ }^{48,49}$. To ensure their successful proliferation, both parties have evolved numerous molecular strategies which are continuously being uncovered. Among the most remarkable recent discoveries are various defense and counter-defense mechanisms ${ }^{9}$, peptide-based communication strategies employed by bacterial viruses to alternate 
between the lytic and lysogenic life $\operatorname{cycles}^{50}$, as well as virusmediated manipulation of the behavior and reproductive strategies of the hosts ${ }^{51,52}$. Horizontal gene transfer plays a key role in these processes, with many, if not all, molecular innovations being shuttled back and forth between viruses and cells, irrespective of who the original inventor was ${ }^{53}$. Indeed, even such hallmark virus components as the major virion proteins have been recurrently exapted from cellular proteomes and occasionally reintroduced to perform diverse cellular functions ${ }^{54}$. Similarly, numerous AMGs have been recruited by viruses from their hosts, enabling viral manipulation of various cellular pathways, and transforming the infected cell into a specialized virion factory. Genes for the core components of translation machinery, namely RPs, until now appeared as the last unbreached boundary between the cellular and viral kingdoms, despite the fact that certain viruses were known to tinker with protein translation by encoding tRNA genes, protein deformylases or tRNA synthetases. Our current work shows that diverse ribosomal proteins are in fact commonly encoded by numerous cultivated and uncultivated viruses with relatively small genomes and offers support for them having an evolutionary fitness advantage for viruses during infection. Notably, virus-encoded RPs appear to be differentially selected for across environments as aquatic viruses are enriched for bS21, bL31, and bL33, whereas phages of animal-associated bacteria are enriched for bS6, uS9, uS15, and HPF (Fig. 2). Although ribosomes are highly stable macromolecular assemblies which retain most of their original components during cellular growth and division ${ }^{55}$, some elements (proteins bS21, bL12, bL9, bL31, and bL33) are highly dynamic, solvent accessible, and among the few proteins that are loosely bound to the ribosome and can be exchanged in vivo between ribosomes ${ }^{55,56}$. These dynamic ribosomal proteins are enriched in viruses, presumably because they are most suited to homologous replacement during infection. Just as in ocean virus AMGs, it appears that viruses coopt and fix not all enzymes in a metabolic pathway, but instead only central regulators or enzymes for key rate-limiting steps in a pathway ${ }^{6,8,57}$. More generally, such selective acquisition of key components of the multisubunit assemblies, such as ribosomes, or recruitment of central regulators of rate-limiting steps in metabolic pathways appears to be a general strategy employed by viruses to optimize the metabolic state of the infected cells and/or to achieve the takeover of the host. Together, these functional and computational findings highlight widespread means by which viruses might modulate translation upon infection and either call into question a commonly used definition for life-the presence/ absence of RPs-or further blur the borders between viruses and cellular life forms. Given that viral metagenomics becomes a major approach in virus discovery ${ }^{58}$ with new RNA and DNA virus genomes and large genome fragments being discovered by the thousands to tens of thousands $8,38,59,60$, we are most certainly bound to discover many more new strategies of host take-over in the near future.

\footnotetext{
Methods

Sequence analyses. All viral genomes were downloaded from viral RefSeq database (ftp://ftp.ncbi.nlm.nih.gov/refseq/release/viral/). A hidden Markov model (HMM) profile was downloaded from the PFAM database (http://pfam.xfam.org/) for each domain listed in Supplementary Table 1. In total, 106 sequence profiles corresponding to distinct ribosomal protein domains were used as seeds to search the proteomes of viruses infecting hosts from the three cellular domains, as well as proteins predicted on viral contigs from two previously published global metagenomic datasets, Global Ocean Virome ${ }^{8}$, and Earth's Virome ${ }^{38}$, which are available at https://img.jgi.doe.gov/cgi-bin/vr/main.cgi and http://datacommons.cyverse.org/ browse/iplant/home/shared/iVirus/GOV. Notably, domain S1, which is repeated 4 to 6 times in the ribosomal protein bS1, is not exclusive to RPs as it is common across diverse RNA-binding proteins and fused to non-ribosomal functional motifs (pfam id: PF00575.18). Thus while domain S1 was found in homologs of vaccinia virus interferon inhibitor $\mathrm{K}^{3} \mathrm{~L}^{61}$, which is conserved in chordopoxviruses belonging
}

to 7 different genera, it was not considered further due to potential functional ambiguity. The domains were identified by HHsearch ${ }^{62}$ with E-value of 1e-5. For isolates, the identified hits were then manually inspected using HHPRED ${ }^{62}$. All alignments were constructed using PROMALS3D ${ }^{63}$. Maximum likelihood phylogenetic trees were constructed using PhyML ${ }^{64}$ using a WAG substitution model and the proportion of invariable sites estimated from the data. For metagenomic predicted proteins, multiple alignments were built with Muscle ${ }^{65}$ and maximum likelihood phylogenetic trees were computed with FastTree ${ }^{66}$, and displayed with $\mathrm{iToL}^{67}$. Genomic comparisons were performed using BLAST with the BLOSUM45 matrix. The ribosomal structure was downloaded from PDB database and visualized using Chimera ${ }^{68}$

Putative temperate phages were identified by searching for the following PFAM domains in ribosomal protein-encoding viral contigs: Mu-transpos_C, Phage_int_SAM_5, and Phage_integrase (hmmsearch, threshold of 30 on bit score). Host predictions for viral metagenomic contig were obtained from the original studies (i.e., ref. ${ }^{8}$ and ${ }^{38}$ ) and, in the case of the Earth's virome ${ }^{38}$, complemented with a k-mer based prediction computed with WIsH ${ }^{69}$ ( $p$-value threshold of 0.001 )

To further confirm the functionality of RPs encoded on uncultivated viral genomes, selective constraint on these AMGs was evaluated through $\mathrm{pN} / \mathrm{pS}$ calculation, as in ref. ${ }^{46}$. Briefly, synonymous and non-synonymous SNPs were observed in each ribosomal protein gene covered $\geq 10 \times$, and compared to expected ratio of synonymous and non-synonymous SNPs under a neutral evolution model if at least $1 \mathrm{SNP}$ was identified. The interpretation of $\mathrm{pN} / \mathrm{pS}$ is similar as for $\mathrm{dN} / \mathrm{dS}$ analyses, with the operation of purifying selection leading to $\mathrm{pN} / \mathrm{pS}$ values $<1$.

Genetic constructions. The genes encoding for bS21 protein from Pelagibacter phage HTVC008M (AGE60443), HPF protein from Escherichia coli bacteriophage rv5 and bL12 protein from Salmonella phage FSL SP-076 (AGF88397) were synthetized by Eurofins Genomics (Ebersberg, Germany). bS21 and HPF genes were cloned into pEX-A2 plasmid and bL12 gene into pEX-K4 plasmid. The gene corresponding to HPF viral protein was digested by BsaI and HindIII and inserted into a pBAD24 vector between NcoI and HindIII restriction sites. The genes corresponding to bS21 and bL12 viral proteins were cloned into the same vector, using EcoRI and HindIII restriction sites. The C-terminal streptavidin-tagged versions of bS21 genes from Pelagibacter phage and E. coli were also synthetized and cloned into pBAD24 plasmids. The pBAD24 plasmid harbors an arabinose dependent promoter, a pBR322 origin and the ampicillin resistance coding sequence.

Protein expression and cell retrieval. Escherichia coli strain NM522 was used for expression of viral bS21, HPF, and bL12 proteins. The same strain harboring empty pBAD24 was used as a negative control. Overnight pre-cultures were grown in the presence of $1 \mathrm{mM}$ of L-arabinose and $100 \mu \mathrm{g} / \mathrm{mL}$ of ampicillin. Then the expression was maintained in the cell culture until the end of exponential phase. Once the cultures reached an $\mathrm{OD}_{600 \mathrm{~nm}}$ of 1 , the cells were centrifuged at $8700 \times \mathrm{g}$ for 7 minutes at $4{ }^{\circ} \mathrm{C}$. The cell pellet was then washed into saline water at a concentration of $9 \mathrm{~g} / \mathrm{L}$ of $\mathrm{NaCl}$. A second centrifugation was made and the bacterial pellet was frozen at $-80^{\circ} \mathrm{C}$.

70S Ribosome purification. The E. coli cells were resuspended in Buffer 1 (Tris$\mathrm{HCl} \mathrm{pH7,5} 20 \mathrm{mM}, \mathrm{MgOAc} 50 \mathrm{mM}^{-N_{4}} \mathrm{Cl}_{100 \mathrm{mM}}$, EDTA $0.5 \mathrm{mM}$ and DTT $1 \mathrm{mM}$ ) and finally lysed using the French Press. The lysate was centrifuged and the supernatant was put above the same volume of high-salt sucrose buffer (Tris- $\mathrm{HCl}$ pH7.5 $10 \mathrm{mM}, \mathrm{MgCl}_{2} 10 \mathrm{mM}, \mathrm{NH}_{4} \mathrm{Cl} 500 \mathrm{mM}$, EDTA $0.5 \mathrm{mM}$, certified RNase free sucrose $1.1 \mathrm{M}$ and DTT $1 \mathrm{mM}$ ) in order to wash the ribosomes. After centrifugation at $93,000 \times g$ for $20 \mathrm{~h}$ at $4{ }^{\circ} \mathrm{C}$ using Type 70 Ti rotor (BECKMAN L-90 ultracentrifuge), the ribosomes form a translucent pellet. The ribosome pellet was washed several times to remove membranes and then resuspended in Buffer 2 (Tris- $\mathrm{HCl}$ pH7.5 $10 \mathrm{mM}, \mathrm{MgCl}_{2} 10 \mathrm{mM}, \mathrm{NH}_{4} \mathrm{Cl} 50 \mathrm{mM}$, EDTA $0.5 \mathrm{mM}$ and DTT $1 \mathrm{mM}$ ) on ice. An equivalent of $200 \mathrm{OD}_{260 \mathrm{~nm}}$ units of ribosomes were loaded on top of a $10-50 \%$ sucrose gradient into polycarbonate tubes. The ultra-centrifugation was performed at $95,000 \times \mathrm{g}$, for $18 \mathrm{~h}$ at $4{ }^{\circ} \mathrm{C}$ using SW28 rotor (BECKMAN L-90 ultracentrifuge). The gradient was then fractionated into $500 \mu \mathrm{L}$ aliquots. The $\mathrm{OD}_{260 \mathrm{~nm}}$ values were determined for each fraction to locate the $70 \mathrm{~S}$ absorbance peak. The corresponding fractions were pooled in one volume of buffer 2 and centrifuged at $93,000 \times g$ for $20 \mathrm{~h}$ at $4{ }^{\circ} \mathrm{C}$ using Type $70 \mathrm{Ti}$ rotor in order to remove sucrose. The pellet was recovered in buffer 2 and after titration, the ribosomes were ready for mass spectrometry analysis or purification using StrepTrap ${ }^{\text {sx }}$ HP columns (GE healthcare) for in vitro translation assays.

The StrepTactin Sepharose column (StrepTrap ${ }^{\text {Tx }}$ HP columns, GE Healthcare Life Sciences) was equilibrated with the buffer 3 (MgOAc $9 \mathrm{mM}, \mathrm{NH}_{4} \mathrm{Cl} 10 \mathrm{mM}$, $\mathrm{KCl} 50 \mathrm{mM}$, HEPES-KOH pH7, $55 \mathrm{mM}$ and DTT $1 \mathrm{mM}$ ). After injection of the purified ribosomes, the column was washed with $100 \mathrm{~mL}$ of buffer 3 before elution with $2.5 \mathrm{mM}$ of d-Desthiobiotin. Fractions containing ribosomes were finally concentrated (Amicon $30 \mathrm{kDa}$ ) and resuspended in the buffer 3 for in vitro translation assays. 
In vitro translation assays. In vitro translation was performed using PURExpress ${ }^{\circledR} \Delta$ Ribosome Kit (New England Biolabs). Wild-type ribosomes (controls) or eluted ribosomes carrying E. coli or virus-encoded tagged bS21 were tested (final concentration: $10 \mathrm{pmol})$. A green fluorescent protein was translated by using a PCR product containing $\mathrm{T} 7$ promoter to rapidly evaluate the translation rates.

Fluorescence analysis. After $3 \mathrm{~h}$ incubation at $37^{\circ} \mathrm{C}$, the reaction volume was adjusted to $125 \mu \mathrm{L}$ and distributed in cuvettes for Fluorescence measurement with LS 55 Fluorescence Spectrometer (PerkinElmer). Fluorescence intensity of translated GFP was determined using the FinLab software with following conditions: $\lambda$ excitation $485 \mathrm{~nm} /$ slit 10/photomultiplicator $775 / \lambda$ emission $510 \mathrm{~nm}$.

Negative staining. Following ribosome separation, we diluted samples 10 times in Buffer 2 and applied them to freshly glow-discharged 300-mesh collodion/carboncoated grids. After three washes in this buffer, grids were stained with $2 \%$ uranyl acetate for $30 \mathrm{~S}$. The grids were then observed with a Tecnai G2 Sphera transmission electron microscope operating at $200 \mathrm{kV}$. Images were recorded with a $4000 \times 4000$ Gatan Ultrascan 4000 CCD camera at a nominal magnification of $\times 50,000$.

Liquid digestion of ribosomal samples. $25 \mu \mathrm{g}$ of ribosomes were digested according to the following protocol: first, $53.5 \mu \mathrm{l}$ of $50 \mathrm{mM}$ ammonium bicarbonate buffer $(\mathrm{pH} 7,8)$ was added to the sample to $65 \mu \mathrm{L}$ total volume. After vortexing 1 minute, tubes were incubated 10 minutes at $80^{\circ} \mathrm{C}$ and then sonicated for two minutes. Reduction of disulfide bonds step was processed by adding $12.5 \mu \mathrm{l}$ of 65 mM DTT to the sample and was incubated 15 minutes at $37^{\circ} \mathrm{C}$ after agitation 1 minute. Alkylation of reduced disulfide bonds was realized by adding $135 \mathrm{mM}$ iodoacetamide. Microtube was then incubated 15 minutes in the dark at room temperature, under agitation. Finally, proteins were digested overnight at $37^{\circ} \mathrm{C}$ with $10 \mu \mathrm{l}$ of either modified endoproteinase glu-c $([0.1 \mu \mathrm{g} / \mu \mathrm{l}$.$] , Promega, Madison,$ WI) in $50 \mathrm{mM}$ ammonium bicarbonate buffer for bS21 (due to high lysine and arginine content in bS21) or with modified Trypsine $([0.1 \mu \mathrm{g} / \mu \mathrm{l}$.$] , Promega,$ Madison, WI) in $50 \mathrm{mM}$ ammonium bicarbonate buffer for HPF, bL12 and control.

Protein prefractionation and digestion. Twenty five micrograms of soluble crude protein extracts of $E$. coli were boiled for $10 \mathrm{~min}$ with $5 \mu \mathrm{l}$ of LDS Sample buffer $4 \mathrm{X}$ and $2 \mu \mathrm{l}$ of reducing agent (DTT $10 \times(500 \mathrm{mM}))$. They were then separated on a NuPAGE $^{\circledast}$ Novex $^{\circledast}$ 4-12 \% gradient Bis-Tris gel (Invitrogen Corparation, USA) in MES SDS Running Buffer (Invitrogen: $50 \mathrm{mM}$ MES, $50 \mathrm{mM}$ Tris- $\mathrm{HCl}, 1 \%$ SDS, 1.025 Mm EDTA) using Xcell SureLock Mini Cell (Invitrogen).

Gel was stained with EZBlue (Sigma-Aldrich) for $30 \mathrm{~min}$ and destained with water overnight. Each gel lane was manually cut into 2 slices of approximately the same size in the region of $7 \mathrm{kDa}-14 \mathrm{kDa}$. The slices were first treated with $50 \mathrm{mM}$ $\mathrm{NH}_{4} \mathrm{HCO}_{3}$ in acetonitrile/water 1:1 (v/v), dehydrated with $100 \%$ acetonitrile and rehydrated in $100 \mathrm{mM} \mathrm{NH}_{4} \mathrm{HCO}_{3}$. Next they were washed again with $50 \mathrm{mM}$ $\mathrm{NH} 4 \mathrm{HCO} 3$ in acetonitrile/water, 1:1 (v/v) and dehydrated with $100 \%$ acetonitrile. The slices were then treated with $65 \mathrm{mM}$ DTT for $15 \mathrm{~min}$ at $37^{\circ} \mathrm{C}$, and with 135 $\mathrm{mM}$ iodoacetamide in the dark at room temperature. Finally, the samples were washed with $100 \mathrm{mM} \mathrm{NH}_{4} \mathrm{HCO}_{3}$ in acetonitrile/water, 1:1 (v/v), and dehydrated with $100 \%$ acetonitrile before being rehydrated in $100 \mathrm{mM} \mathrm{NH}_{4} \mathrm{HCO}_{3}$, washed with $100 \mathrm{mM} \mathrm{NH}_{4} \mathrm{HCO}_{3}$ in acetonitrile/water, 1:1 (v/v) and then dehydrated again with $100 \%$ acetonitrile. Proteins were digested overnight at $37^{\circ} \mathrm{C}$ with $4 \mathrm{ng} / \mathrm{l}$ of modified trypsin (Promega, Madison, WI) in $50 \mathrm{mM} \mathrm{NH}_{4} \mathrm{HCO}_{3}$. Peptides were extracted by incubating the slices first in $80 \mu \mathrm{l}$ of acetonitrile/ water/trifluoroacetic acid $(70 / 30 / 0.1 ; \mathrm{v} / \mathrm{v} / \mathrm{v})$ for $20 \mathrm{~min}$, and then in $40 \mu \mathrm{l}$ of $100 \%$ acetonitrile for $5 \mathrm{~min}$ and finally in $40 \mu \mathrm{l}$ of acetonitrile/water/trifluoroacetic acid (70/30/0.1; v/v/v) for $15 \mathrm{~min}$. Supernatants were transferred into fresh tubes and concentrated in a SpeedVac (Thermo Scientific) for $15 \mathrm{~min}$ to a final volume of $40 \mu \mathrm{l}$.

LC-MS/MS analysis. Shotgun analyses were conducted on a LTQ-Orbitrap XL (ThermoFisher Scientific) mass spectrometer. The MS measurements were done with a nanoflow highperformance liquid chromatography (HPLC) system (Dionex, LC Packings Ultimate 3000) connected to a hybrid LTQ-Orbitrap XL (Thermo Fisher Scientific) equipped with a nanoelectrospray ion source (New Objective). The HPLC system consisted of a solvent degasser nanoflow pump, a thermostated column oven kept at $30^{\circ} \mathrm{C}$, and a thermostated autosampler kept at $8{ }^{\circ} \mathrm{C}$ to reduce sample evaporation. Mobile A (99.9\% Milli-Q water and $0.1 \%$ formic acid (v:v)) and B (99.9\% acetonitrile and $0.1 \%$ formic acid (v:v)) phases for HPLC were delivered by the Ultimate 3000 nanoflow LC system (Dionex, LC Packings). An aliquot of $10 \mu \mathrm{L}$ of prepared peptide mixture was loaded onto a trapping precolumn $(5 \mathrm{~mm} \times 300 \mu \mathrm{m}$ i.d., $300 \AA$ pore size, Pepmap C18, $5 \mu \mathrm{m})$ over $3 \mathrm{~min}$ in $2 \%$ buffer $\mathrm{B}$ at a flow rate of $25 \mu \mathrm{L} / \mathrm{min}$. This step was followed by reverse-phase separations at a flow rate of $0.250 \mu \mathrm{L} / \mathrm{min}$ using an analytical column $(15 \mathrm{~cm} \times 300$ $\mu \mathrm{m}$ i.d., $300 \AA$ pore size, Pepmap C18, $5 \mu \mathrm{m}$, Dionex, LC Packings). We ran a gradient from $2-35 \%$ buffer B for the first $60 \mathrm{~min}, 35-60 \%$ buffer B from minutes $60-85$, and $60-90 \%$ buffer B from minutes $85-105$. Finally, the column was washed with $90 \%$ buffer B for 16 min and with $2 \%$ buffer B for 19 min before the next sample was loaded. The peptides were detected by directly eluting them from the HPLC column into the electrospray ion source of the mass spectrometer. An electrospray ionization (ESI) voltage of $1.6 \mathrm{kV}$ was applied to the HPLC buffer using the liquid junction provided by the nanoelectrospray ion source, and the ion transfer tube temperature was set to $200^{\circ} \mathrm{C}$. The LTQ-Orbitrap XL instrument was operated in its data-dependent mode by automatically switching between full survey scan MS and consecutive MS/MS acquisitions. Survey full scan MS spectra (mass range 400-2000) were acquired in the Orbitrap section of the instrument with a resolution of $r=60000$ at $\mathrm{m} / \mathrm{z} 400$; ion injection times were calculated for each spectrum to allow for accumulation of $10^{6}$ ions in the Orbitrap. The ten most intense peptide ions in each survey scan with an intensity above 2000 counts (to avoid triggering fragmentation too early during the peptide elution profile) and a charge state $\geq 2$ were sequentially isolated at a target value of 10,000 and fragmented in the linear ion trap by collision-induced dissociation. Normalized collision energy was set to $35 \%$ with an activation time of $30 \mathrm{~ms}$. Peaks selected for fragmentation were automatically put on a dynamic exclusion list for $30 \mathrm{~S}$ with a mass tolerance of $\pm 10 \mathrm{ppm}$ to avoid selecting the same ion for fragmentation more than once. The following parameters were used: the repeat count was set to 1 , the exclusion list size limit was 500, singly charged precursors were rejected, and the maximum injection time was set at 500 and $300 \mathrm{~ms}$ for full MS and MS/MS scan events, respectively. For an optimal duty cycle, the fragment ion spectra were recorded in the LTQ mass spectrometer in parallel with the Orbitrap full scan detection.

For Orbitrap measurements, an external calibration was used before each injection series ensuring an overall error mass accuracy below $5 \mathrm{ppm}$ for the detected peptides. MS data were saved in RAW file format (Thermo Fisher Scientific) using XCalibur 2.0.7 with tune 2.4. The data analysis was performed with Proline software 1.4 supported by Mascot Distiller and Mascot server (v2.5.1; http://www.matrixscience.com) database search engine for peptide and protein identification using its automatic decoy database search to calculate a false discovery rate (FDR) of $1 \%$ at the peptide level. MS/MS spectra were compared to the Escherichia coli Reference proteome set database containing the phage ribosomal proteins (UniProt release 2017_01, 18 January 2017, 23022 sequences, 7070297 residues). Mass tolerance for MS and MS/MS was set at $10 \mathrm{ppm}$ and $0.5 \mathrm{Da}$, respectively. The enzyme selectivity was set to full trypsin with one miscleavage allowed for samples HPF and bL12 and the enzyme selectivity was set to full V8-DE with one miscleavage allowed for sample bS21.

Protein modifications were fixed carbamidomethylation of cysteines, variable oxidation of methionine, variable acetylation of lysine, and variable acetylation of $\mathrm{N}$-terminal residues.

Reporting summary. Further information on experimental design is available in the Nature Research Reporting Summary linked to this article.

\section{Data availability}

The authors declare that the data supporting the findings of this study are available within the paper and its supplementary information files. Viral contigs analyzed in this study are from two previously published global metagenomic datasets (Global Ocean Virome and Earth's Virome) that are available at https://img.jgi.doe.gov/cgi-bin/vr/main cgi and http://datacommons.cyverse.org/browse/iplant/home/shared/iVirus/GOV

Received: 22 September 2017 Accepted: 18 January 2019 Published online: 14 February 2019

\section{References}

1. Lindell, D., Jaffe, J. D., Johnson, Z. I., Church, G. M. \& Chisholm, S. W. Photosynthesis genes in marine viruses yield proteins during host infection. Nature 438, 86-89 (2005).

2. Fridman, S. et al. A myovirus encoding both photosystem I and II proteins enhances cyclic electron flow in infected Prochlorococcus cells. Nat. Microbiol 2, 1350-1357 (2017).

3. Hurwitz, B. L., Hallam, S. J. \& Sullivan, M. B. Metabolic reprogramming by viruses in the sunlit and dark ocean. Genome Biol. 14, R123 (2013).

4. Sullivan, M. B. et al. Genomic analysis of oceanic cyanobacterial myoviruses compared with T4-like myoviruses from diverse hosts and environments. Environ. Microbiol. 12, 3035-3056 (2010).

5. Hurwitz, B. L., Brum, J. R. \& Sullivan, M. B. Depth-stratified functional and taxonomic niche specialization in the 'core' and 'flexible' Pacific Ocean Virome. ISME J. 9, 472-484 (2015)

6. Thompson, L. R. et al. Phage auxiliary metabolic genes and the redirection of cyanobacterial host carbon metabolism. Proc. Natl Acad. Sci. USA 108 E757-E764 (2011)

7. Anantharaman, K. et al. Sulfur oxidation genes in diverse deep-sea viruses Science 344, 757-760 (2014)

8. Roux, S. et al. Ecogenomics and potential biogeochemical impacts of globally abundant ocean viruses. Nature 537, 689-693 (2016). 
9. Sontheimer, E. J. \& Davidson, A. R. Inhibition of CRISPR-Cas systems by mobile genetic elements. Curr. Opin. Microbiol. 37, 120-127 (2017).

10. Stanley, S. Y., . \& Maxwell, K. L. Phage-Encoded Anti-CRISPR Defenses. Annu. Rev. Genet. 23, 445-464 (2018).

11. Nechaev, S. \& Severinov, K. Bacteriophage-induced modifications of host RNA polymerase. Annu. Rev. Microbiol. 57, 301-322 (2003).

12. Colson, P., Fournous, G., Diene, S. M. \& Raoult, D. Codon usage, amino acid usage, transfer RNA and amino-acyl-tRNA synthetases in Mimiviruses. Intervirology 56, 364-375 (2013).

13. Miller, E. S. et al. Bacteriophage T4 genome. Microbiol. Mol. Biol. Rev. 67, 86-156 (2003)

14. Sencilo, A. et al. Snapshot of haloarchaeal tailed virus genomes. RNA Biol. 10, 803-816 (2013).

15. Bailly-Bechet, M., Vergassola, M. \& Rocha, E. Causes for the intriguing presence of tRNAs in phages. Genome Res. 17, 1486-1495 (2007).

16. Enav, H., Beja, O. \& Mandel-Gutfreund, Y. Cyanophage tRNAs may have a role in cross-infectivity of oceanic Prochlorococcus and Synechococcus hosts. ISME J. 6, 619-628 (2012).

17. Raoult, D. et al. The 1.2-megabase genome sequence of Mimivirus. Science 306, 1344-1350 (2004)

18. Schulz, F. et al. Giant viruses with an expanded complement of translation system components. Science 356, 82-85 (2017).

19. Abrahão, J. S., Araujo, R., Colson, P. \& La Scola, B. The analysis of translationrelated gene set boosts debates around origin and evolution of mimiviruses. PLoS Genet. 13, e1006532 (2017).

20. Abergel, C., Rudinger-Thirion, J., Giege, R. \& Claverie, J. M. Virus-encoded aminoacyl-tRNA synthetases: structural and functional characterization of mimivirus TyrRS and MetRS. J. Virol. 81, 12406-12417 (2007).

21. Hendrix, R. W. Jumbo bacteriophages. Curr. Top. Microbiol. Immunol. 328 229-240 (2009).

22. Sharon, I. et al. Comparative metagenomics of microbial traits within oceanic viral communities. ISME J. 5, 1178-1190 (2011).

23. Frank, J. A. et al. Structure and function of a cyanophage-encoded peptide deformylase. ISME J. 7, 1150-1160 (2013).

24. Robertson, E. S., Aggison, L. A. \& Nicholson, A. W. Phosphorylation of elongation factor $\mathrm{G}$ and ribosomal protein $\mathrm{S} 6$ in bacteriophage T7-infected Escherichia coli. Mol. Microbiol. 11, 1045-1057 (1994).

25. Robertson, E. S. \& Nicholson, A. W. Phosphorylation of Escherichia coli translation initiation factors by the bacteriophage T7 protein kinase. Biochemistry 31, 4822-4827 (1992).

26. Forterre, P., Krupovic, M. \& Prangishvili, D. Cellular domains and viral lineages. Trends Microbiol. 22, 554-558 (2014).

27. Raoult, D. \& Forterre, P. Redefining viruses: lessons from Mimivirus. Nat. Rev. Microbiol. 6, 315-319 (2008)

28. Roux, S., Krupovic, M., Debroas, D., Forterre, P. \& Enault, F. Assessment of viral community functional potential from viral metagenomes may be hampered by contamination with cellular sequences. Open Biol. 3, 130160 (2013).

29. Ban, N. et al. A new system for naming ribosomal proteins. Curr. Opin. Struct. Biol. 24, 165-169 (2014).

30. Michiels, L., Van der Rauwelaert, E., Van Hasselt, F., Kas, K. \& Merregaert, J. fau cDNA encodes a ubiquitin-like-S30 fusion protein and is expressed as an antisense sequence in the Finkel-Biskis-Reilly murine sarcoma virus. Oncogene 8, 2537-2546 (1993).

31. Mourtada-Maarabouni, M., Kirkham, L., Farzaneh, F. \& Williams, G. T. Regulation of apoptosis by fau revealed by functional expression cloning and antisense expression. Oncogene 23, 9419-9426 (2004).

32. Van Duin, J. \& Wijnands, R. The function of ribosomal protein S21 in protein synthesis. Febs. J. 118, 615-619 (1981).

33. Morris, R. M. et al. SAR11 clade dominates ocean surface bacterioplankton communities. Nature 420, 806-810 (2002).

34. Atkins, J. F. \& Bjork, G. R. A. gripping tale of ribosomal frameshifting: extragenic suppressors of frameshift mutations spotlight P-site realignment. Microbiol. Mol. Biol. Rev. 73, 178-210 (2009).

35. Hoffman, D. W., Cameron, C. S., Davies, C., White, S. W. \& Ramakrishnan, V. Ribosomal protein L9: a structure determination by the combined use of X-ray crystallography and NMR spectroscopy. J. Mol. Biol. 264, 1058-1071 (1996).

36. Gudkov, A. The L7/L12 ribosomal domain of the ribosome: structural and functional studies. FEBS Lett. 407, 253-256 (1997).

37. Trauner, A., Lougheed, K. E., Bennett, M. H., Hingley-Wilson, S. M. \& Williams, H. D. The dormancy regulator DosR controls ribosome stability in hypoxic mycobacteria. J. Biol. Chem. 287, 24053-24063 (2012).

38. Paez-Espino, D. et al. Uncovering Earth's virome. Nature 536, 425-430 (2016).

39. Maguire, B. A. \& Wild, D. G. The roles of proteins L28 and L33 in the assembly and function of Escherichia coli ribosomes in vivo. Mol. Microbiol. 23, 237-245 (1997).
40. Korepanov, A. P., Korobeinikova, A. V., Shestakov, S. A., Garber, M. B. \& Gongadze, G. M. Protein L5 is crucial for in vivo assembly of the bacterial $50 \mathrm{~S}$ ribosomal subunit central protuberance. Nucleic Acids Res. 40, 9153-9159 (2012).

41. Ueta, M., Wada, C., Bessho, Y., Maeda, M. \& Wada, A. Ribosomal protein L31 in Escherichia coli contributes to ribosome subunit association and translation, whereas short L31 cleaved by protease 7 reduces both activities. Genes. Cells 22, 452-471 (2017).

42. Rosenwasser, S., Ziv, C., Creveld, S. G. \& Vardi, A. Virocell metabolism: metabolic innovations during host-virus interactions in the ocean. Trends Microbiol. 24, 821-832 (2016)

43. Franceschelli, J. J., Suarez, C. A., Teran, L., Raya, R. R. \& Morbidoni, H. R. Complete genome sequences of nine mycobacteriophages. Genome Announc. 2, e00181-00114 (2014)

44. Xu, J., Hendrix, R. W. \& Duda, R. L. Conserved translational frameshift in dsDNA bacteriophage tail assembly genes. Mol. Cell 16, 11-21 (2004).

45. Howard-Varona, C. et al. Regulation of infection efficiency in a globally abundant marine Bacteriodetes virus. ISME J. 11, 284-295 (2017).

46. Schloissnig, S. et al. Genomic variation landscape of the human gut microbiome. Nature 493, 45-50 (2013).

47. Mehta, P., Woo, P., Venkataraman, K. \& Karzai, A. W. Ribosome purification approaches for studying interactions of regulatory proteins and RNAs with the ribosome. Methods Mol. Biol. 905, 273-289 (2012).

48. Forterre, P. \& Prangishvili, D. The great billion-year war between ribosomeand capsid-encoding organisms (cells and viruses) as the major source of evolutionary novelties. Ann. N. Y. Acad. Sci. 1178, 65-77 (2009).

49. Koonin, E. V. \& Dolja, V. V. A. virocentric perspective on the evolution of life. Curr. Opin. Virol. 3, 546-557 (2013).

50. Erez, Z. et al. Communication between viruses guides lysis-lysogeny decisions. Nature 541, 488-493 (2017)

51. Dheilly, N. M. et al. Who is the puppet master? Replication of a parasitic wasp-associated virus correlates with host behaviour manipulation. Proc. Biol. Sci. 282, 20142773 (2015).

52. LePage, D. P. et al. Prophage WO genes recapitulate and enhance Wolbachiainduced cytoplasmic incompatibility. Nature 543, 243-247 (2017).

53. Koonin, E. V. \& Krupovic, M. A movable defense. Scientist 29, 46-53 (2015)

54. Krupovic, M. \& Koonin, E. V. Multiple origins of viral capsid proteins from cellular ancestors. Proc. Natl Acad. Sci. USA 114, E2401-E2410 (2017).

55. Subramanian, A.-R. \& van Duin, J. Exchange of individual ribosomal proteins between ribosomes as studied by heavy isotope-transfer experiments. Mol. Gen. Genet. 158, 1-9 (1977)

56. Yamamoto, T., Izumi, S. \& Gekko, K. Mass spectrometry of hydrogen/ deuterium exchange in 70 s ribosomal proteins from E. coli. FEBS Lett. $\mathbf{5 8 0}$, 3638-3642 (2006)

57. Lindell, D. et al. Genome-wide expression dynamics of a marine virus and host reveal features of co-evolution. Nature 449, 83-86 (2007).

58. Simmonds, P. et al. Consensus statement: virus taxonomy in the age of metagenomics. Nat. Rev. Microbiol. 15, 161-168 (2017)

59. Shi, M. et al. Redefining the invertebrate RNA virosphere. Nature 540, 539-543 (2016).

60. Emerson, J. B. et al. Host-linked soil viral ecology along a permafrost thaw gradient. Nat. Microbiol 3, 870-880 (2018).

61. Dar, A. C. \& Sicheri, F. X-ray crystal structure and functional analysis of vaccinia virus K3L reveals molecular determinants for PKR subversion and substrate recognition. Mol. Cell 10, 295-305 (2002).

62. Söding, J. Protein homology detection by HMM-HMM comparison. Bioinformatics 21, 951-960 (2005)

63. Pei, J., Kim, B. H. \& Grishin, N. V. PROMALS3D: a tool for multiple protein sequence and structure alignments. Nucleic Acids Res. 36, 2295-2300 (2008).

64. Guindon, S. et al. New algorithms and methods to estimate maximumlikelihood phylogenies: assessing the performance of PhyML 3.0. Syst. Biol. 59, 307-321 (2010).

65. Edgar, R. C. MUSCLE: multiple sequence alignment with high accuracy and high throughput. Nucleic Acids Res. 32, 1792-1797 (2004).

66. Price, M. N., Dehal, P. S. \& Arkin, A. P. FastTree 2-approximately maximum-likelihood trees for large alignments. PLoS ONE 5, e9490 (2010).

67. Letunic, I. \& Bork, P. Interactive tree of life (iTOL) v3: an online tool for the display and annotation of phylogenetic and other trees. Nucleic Acids Res. 44, W242-245 (2016).

68. Pettersen, E. F. et al. UCSF Chimera-a visualization system for exploratory research and analysis. J. Comput. Chem. 25, 1605-1612 (2004).

69. Galiez, C., Siebert, M., Enault, F., Vincent, J. \& Söding, J. WIsH: who is the host? Predicting prokaryotic hosts from metagenomic phage contigs. Bioinformatics 33, 3113-3114 (2017).

\section{Acknowledgements}

This work was supported by grant ERC UE 340440 to PF; Agence Nationale pour la Recherche grants to M.K. (\#ANR-17-CE15-0005-01) and R.G. (Direction Générale de 
l'Armement; \#ANR-14-ASTR-0001); the Virus-X project (EU Horizon 2020, No. 685778) to M.K.. C.M.M. was supported by the European Molecular Biology Organization (ALTF 15622015) and Marie Curie Actions program from the European Commission (LTFCOFUND2013, GA-2013-609409); C.G. was supported by Direction Générale de l'Armement and Ministère de l'Enseignement supérieur et de la Recherche; M.B.S. was supported by Gordon and Betty Moore Foundation (\#3305, 3790) and National Science Foundation (OCE\#1536989) awards. F.R.-V. was supported by grant VIREVO CGL2016-76273-P [AEI/ FEDER, EU] (cofounded with FEDER funds). The work conducted by the U.S. Department of Energy Joint Genome Institute, a DOE Office of Science User Facility, is supported under Contract No. DE-AC02-05CH11231. We thank Fanny Demay for the technical assistance and Sophie Chat for help with electron microscopy.

\section{Author contributions}

M.K. conceived the study. C.M.M. and S.R. performed sequence analyses. C.M.M., S.R., M.B.S. and M.K. interpreted the results. C.G. and R.G. planned and performed functional assays. R.L. performed LC-MS/MS analysis. F.R.-V. and P.F. contributed resources. C.M.M. and M.K. wrote the first draft of the manuscript, with substantial contribution from S.R. M.B.S. and R.G. All authors edited and approved the final version of the manuscript.

\section{Additional information}

Supplementary Information accompanies this paper at https://doi.org/10.1038/s41467019-08672-6

Competing Interests: The authors declare no competing interests.
Reprints and permission information is available online at http://npg.nature.com/ reprintsandpermissions/

Journal peer review information:Nature Communications thanks the anonymous reviewers for their contribution to the peer review of this work. Peer reviewer reports are available.

Publisher's note: Springer Nature remains neutral with regard to jurisdictional claims in published maps and institutional affiliations.

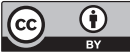

Open Access This article is licensed under a Creative Commons Attribution 4.0 International License, which permits use, sharing, adaptation, distribution and reproduction in any medium or format, as long as you give appropriate credit to the original author(s) and the source, provide a link to the Creative Commons license, and indicate if changes were made. The images or other third party material in this article are included in the article's Creative Commons license, unless indicated otherwise in a credit line to the material. If material is not included in the article's Creative Commons license and your intended use is not permitted by statutory regulation or exceeds the permitted use, you will need to obtain permission directly from the copyright holder. To view a copy of this license, visit http://creativecommons.org/ licenses/by/4.0/.

(C) The Author(s) 2019 